\title{
Optimising glucocorticoid replacement in adrenal insufficiency
}

\author{
KARIM MEERAN
}

\begin{abstract}
Several different regimens for steroid replacement have been tried, but head to head studies of different treatments need to be more widely undertaken. Once daily treatment with prednisolone gives the most physiological profile, and studies comparing prednisolone with hydrocortisone are now being undertaken. It is likely that prednisolone $4 \mathrm{mg}$ daily will be the optimum treatment used.

Br J Diabetes 2019;19:131-132
\end{abstract}

Key words: prednisolone, Addison's disease, hydrocortisone, cortisol, pituitary, fludrocortisone

It is well known that steroid replacement with glucocorticoids saves lives in patients with adrenal insufficiency. Excess glucocorticoid exposure, as evidenced by patients with Cushing's syndrome, can also be fatal. There remains an increased mortality associated with adrenal insufficiency despite glucocorticoid replacement therapy with a standardised mortality ratio of $>2$. The cause of the increased mortality is yet to be definitively elucidated, but may be due to excess steroid exposure or replacement regimens that are uncoupled from the normal physiological cortisol profile. Remarkably, there is no agreement on how we can optimise replacement therapy for either primary or secondary adrenal insufficiency.

Uncoupling glucocorticoid dose timing from the normal circadian cortisol rhythm can be harmful. ${ }^{1,2}$ Human cells have developed circadian clocks that are kept in synchrony by the hypothalamicpituitary adrenal (HPA) axis. ${ }^{3}$ Cortisol levels rise at around 04:00 hours, under the influence of the central circadian pacemaker in the hypothalamus driven by ACTH. Misalignment between cortisol levels and clock time is one of the factors contributing to the adverse health outcomes seen in shift workers and problems associated with jet lag. ${ }^{4}$

It is not known how closely we need to mimic the endogenous rhythm of cortisol when we replace glucocorticoids in patients with pituitary or adrenal failure. Normally the HPA axis has both an ultradian and a circadian rhythm. The ultradian rhythm of irregular pulses of activity can only be mimicked with a pump. Mimicking

Address for correspondence: Professor Karim Meeran Professor of Endocrinology, Deputy Director of Medical Education and Lead Clinician for Endocrinology, Endocrine Unit, 9th floor, Charing Cross campus, Imperial College, Fulham Palace Road, London W6 8RF E-mail:k.meeran@ic.ac.uk

https://doi.org/10.15277/bjd.2019.229 the circadian rhythm accurately would require levels of cortisol to rise before waking, and this can be reproduced either with a pump or with a delayed release oral tablet.

The excess replacement that frequently occurs with twice or thrice daily hydrocortisone is associated with an increase in cardiovascular deaths in these patients, especially with escalating doses, ${ }^{5}$ and the late peaks in cortisol might be harmful. ${ }^{6} \mathrm{~A}$ delayed release preparation (Chronocort) taken last thing at night ${ }^{7}$ has the theoretical advantage of mimicking the early morning 04:00 hours rise in cortisol, which cannot be achieved with other preparations.

Another strategy available in some countries is the use of dual release hydrocortisone (Plenadren) once daily first thing in the morning. This extremely expensive sustained release preparation fails to replicate the pre-awakening rise in cortisol and we know very little about what happens to blood or tissue levels of cortisol overnight. It relies on continuous absorption of hydrocortisone from the gut which can be variable, a problem that must be guarded against in patients with infectious diarrhoea, when glucocorticoids are crucial. ${ }^{8}$ The manufacturers state that Plenadren is commonly associated (>1 in 10 cases) with gastrointestinal side effects. ${ }^{9}$

Comparison of twice-daily cortisone acetate with once-daily slow release hydrocortisone in the DREAM study ${ }^{10}$ suggests that a once-daily preparation has fewer side effects than twice-daily cortisone acetate. Lower doses of glucocorticoids have fewer side effects than higher doses. In terms of concentration of glucocorticoids in the blood, once-daily prednisolone has been shown to mimic the circadian rhythm better than any other oral glucocorticoid. ${ }^{11}$ A double-blind randomised controlled trial comparing hydrocortisone $15 \mathrm{mg}$ in the morning plus $5 \mathrm{mg}$ hydrocortisone at sunset in patients who were fasting for Ramadan found no difference between this and prednisolone $5 \mathrm{mg}$ at dawn and placebo at sunset. ${ }^{12}$

An open-label study has also found no difference in markers of health such as blood pressure and cholesterol, ${ }^{13}$ but found increased satisfaction in patients because they only needed to take medication once daily and found this significantly more convenient $(\mathrm{p}=0.048)$.

Prednisolone is rapidly absorbed and has a prolonged cellular effect. Whether this theoretical advantage of prednisolone is clinically useful and results in reduced risk of adrenal crisis is unknown. It is clear that previously used doses of prednisolone have been excessive and 3-4 mg once daily is sufficient replacement in most patients. ${ }^{13,14}$ Low-dose prednisolone has been shown to be superior in reducing androgens, 17-hydroxy progesterone and improving growth velocity in patients with congenital adrenal hyperplasia compared with thrice-daily hydrocortisone. ${ }^{15}$ 


\section{Key messages}

- Patients with Addison's disease should be prescribed prednisolone $3 \mathrm{mg}$ to $4 \mathrm{mg}$ once daily together with fludrocortisone $100 \mathrm{mcg}$ daily

- Pump therapy for cortisol has not been shown to be beneficial in blinded studies

From a patient's perspective, infusion pumps are less convenient than tablets. Infusion pumps have been used to mimic the circadian rise in morning cortisol. In addition to normalising morning $\mathrm{ACTH}$ levels in patients with primary adrenal failure, improvements in physical functioning and vitality domains of the SF-36 have been noted in open-label studies. ${ }^{16,17}$ In double-blind placebo-controlled conditions, when compared with oral hydrocortisone treatment, the subjective health outcome benefits of pumps are no longer detectable. ${ }^{18}$ These studies were performed without any pulsatile or ultradian patterns. Ultradian pulses might have subtle effects on cognition, although long-term benefits have not been proven. ${ }^{19}$

\section{Conclusion}

Studies comparing different regimens are urgently needed. There are at least three studies comparing prednisolone with hydrocortisone being undertaken at present, ${ }^{20-22}$ and the results of one of these is now in press as of October 2019. ${ }^{21}$ If you are interested in taking part in one of these, please e-mail us on steroids@imperial.ac.uk.

With our present state of knowledge, the optimum, easiest and most cost-effective replacement for patients with pituitary insufficiency requiring glucocorticoid seems to be once-daily prednisolone 3-4 mg and, for those with Addison's disease, prednisolone 3-4 mg daily with fludrocortisone $100 \mu \mathrm{g}$ daily. ${ }^{23}$

This is an accompanying article of a talk given at the Royal Society of Medicine in London on 13 June 2019 on "New technologies in diabetes".

\section{Conflict of interest: None Funding: None}

\section{References}

1. Nicolaides NC, Charmandari E, Kino T, Chrousos GP. Stress-related and circadian secretion and target tissue actions of glucocorticoids: impact on health. Front Endocrinol (Lausanne) 2017;8:70. https://doi.org/ 10.3389/fendo.2017.00070

2. Charmandari E, Nicolaides NC, Chrousos GP. Adrenal insufficiency. Lancet 2014;383(9935):2152-67. https://doi.org/10.1016/S01406736(13)61684-0

3. Charmandari E, Chrousos GP, Lambrou Gl, et al. Peripheral CLOCK regulates target-tissue glucocorticoid receptor transcriptional activity in a circadian fashion in man. PLoS One 2011;6(9):e25612. https://doi.org/ 10.1371/journal.pone.0025612

4. Monk TH, Buysse DJ. Exposure to shift work as a risk factor for diabetes. J Biol Rhythms 2013;28(5):356-9. https://doi.org/10.1177/ 0748730413506557
5. Sherlock M, Reulen RC, Alonso AA, et al. ACTH deficiency, higher doses of hydrocortisone replacement, and radiotherapy are independent predictors of mortality in patients with acromegaly. $J$ Clin Endocrinol Metab 2009;94(11):4216-23. https://doi.org/10.1210/jc.2009-1097

6. Muller L, Quinkler M. Adrenal disease: imitating the cortisol profile improves the immune system. Nat Rev Endocrinol 2018;14(3):137-9. https://doi.org/10.1038/nrendo.2018.5

7. Whitaker M, Debono M, Huatan H, Merke D, Arlt W, Ross RJ. An oral multiparticulate, modified-release, hydrocortisone replacement therapy that provides physiological cortisol exposure. Clin Endocrinol (Oxf) 2014;80(4):554-61. https://doi.org/10.1111/cen.12316

8. Allolio B. Extensive expertise in endocrinology. Adrenal crisis. Eur J Endocrino/ 2015;172(3):R115-24. https://doi.org/10.1530/EJE-14-0824

9. Shire Pharmaceuticals. Plenadren. Summary of product characteristics. https://www.ema.europa.eu/documents/product-information/plenadrenepar-product-information_en.pdf

10. Isidori AM, Venneri MA, Graziadio C, et al. Effect of once-daily, modified-release hydrocortisone versus standard glucocorticoid therapy on metabolism and innate immunity in patients with adrenal insufficiency (DREAM): a single-blind, randomised controlled trial. Lancet Diabetes Endocrinol 2018;6:173-85. https://doi.org/10.1016/\$2213-8587(17)30398-4

11. Williams EL, Choudhury S, Tan T, Meeran K. Prednisolone replacement therapy mimics the circadian rhythm more closely than other glucocorticoids. J App/ Lab Med 2016;1(2):152-61. https://doi.org/10.1373/ jalm.2016.020206

12. Chihaoui M, Mimita W, Oueslati I, et al. Prednisolone or hydrocortisone replacement in patients with corticotrope deficiency fasting during Ramadan result in similar risks of complications and quality of life: a randomised double-blind controlled trial. Endocrine 2019 Sep 24 [Epub ahead of press]. https://doi.org/10.1007/s12020-019-02082-w

13. Smith DJF, Prabhudev H, Choudhury S, Meeran K. Prednisolone has the same cardiovascular risk profile as hydrocortisone in glucocorticoid replacement. Endocr Connect 2017;6(8):766-72. https://doi.org/ 10.1530/EC-17-0257

14. Choudhury S, Machenahalli P, Tan T, Meeran K. Inadvertent treatment of hypoadrenalism with prednisolone in pemphigus: a case report. Clin Case Rep 2019;7(5):987-9. https://doi.org/10.1002/ccr3.2132

15. Caldato MC, Fernandes VT, Kater CE. One-year clinical evaluation of single morning dose prednisolone therapy for 21-hydroxylase deficiency. Arq Bras Endocrinol Metabol 2004;48(5):705-12. https://doi.org/ 10.1590/s0004-27302004000500017

16. Lovas K, Husebye ES. Continuous subcutaneous hydrocortisone infusion in Addison's disease. Eur J Endocrinol 2007;157(1):109-12. https://doi.org/10.1530/EJE-07-0052

17. Oksnes M, Bjornsdottir S, Isaksson M, et al. Continuous subcutaneous hydrocortisone infusion versus oral hydrocortisone replacement for treatment of addison's disease: a randomized clinical trial. J Clin Endocrinol Metab 2014;99(5):1665-74. https://doi.org/10.1210/jc.2013-4253

18. Gagliardi L, Nenke MA, Thynne TR, et al. Continuous subcutaneous hydrocortisone infusion therapy in Addison's disease: a randomized, placebo-controlled clinical trial. J Clin Endocrinol Metab 2014; 99(11):4149-57. https://doi.org/10.1210/jc.2014-2433

19. Kalafatakis K, Russell GM, Harmer CJ, et al. Ultradian rhythmicity of plasma cortisol is necessary for normal emotional and cognitive responses in man. Proc Natl Acad Sci USA 2018;115(17):E4091-100. https://doi.org/10.1073/pnas.1714239115

20. Imperial College London. Safety and efficacy of prednisolone in adrenal insufficiency disease (PRED-AID study). Published 28 January 2019. Updated 2019. Available at: http://www.isrctn.com/ISRCTN41325341 (accessed 19 April 2019)

21. Imperial College London. Hydrocortisone vs prednisolone in AI (HYPERAID). Published 1 August 2018. Updated 2019. Available at: https://clinicaltrials.gov/ct2/show/NCT03608943 (accessed 19 April 2019).

22. Ramadan fasting in patients with corticotrope deficiency treated either by hydrocortisone or by prednisolone. Available at: https:// clinicaltrials.gov/ct2/show/NCT03585829

23. Amin A, Sam AH, Meeran K. Glucocorticoid replacement. BMJ 2014;349:g4843. https://doi.org/10.1136/bmj.g4843 